Georgia State University

ScholarWorks @ Georgia State University

\title{
Cognitive defusion and self-relevant negative thoughts: Examining the impact of a ninety year old technique
}

Akihiko Masuda

Georgia State University, amasuda@gsu.edu

S. C. Hayes

C. F. Sackett

M. P. Twohig

Follow this and additional works at: https://scholarworks.gsu.edu/psych_facpub

Part of the Psychology Commons

\section{Recommended Citation}

Masuda, Akihiko; Hayes, S. C.; Sackett, C. F.; and Twohig, M. P., "Cognitive defusion and self-relevant negative thoughts: Examining the impact of a ninety year old technique" (2004). Psychology Faculty Publications. 81.

https://scholarworks.gsu.edu/psych_facpub/81

This Article is brought to you for free and open access by the Department of Psychology at ScholarWorks @ Georgia State University. It has been accepted for inclusion in Psychology Faculty Publications by an authorized administrator of ScholarWorks @ Georgia State University. For more information, please contact scholarworks@gsu.edu. 
Cognitive defusion and self-relevant negative thoughts: examining the impact of a ninety year old technique

Akihiko Masuda, Steven C. Hayes, Casey F. Sackett, Michael P. Twohig

University of Nevada, Reno, NV 89557-0062, USA

\begin{abstract}
Cognitive defusion techniques are designed to reduce the functions of thoughts by altering the context in which they occur, rather than the attempting to alter the form, frequency, or situational sensitivity of the thoughts themselves. Applied technologies designed to produce cognitive defusion seem to lead to reductions in the believability of negative thoughts, but defusion techniques are generally only parts of complex packages and the role of defusion techniques per se is not yet known. The present study examined the impact of a cognitive defusion technique first described by Titchener nearly 90 years ago: rapidly repeating a single word. In series of eight single-case alternating treatment designs, this defusion technique was compared to a distraction task, and to a thought control task on reductions in the discomfort and believability of self-relevant negative thoughts. The cognitive defusion technique reduced both discomfort and believability more so than the comparison approaches. Control studies showed that the effect was probably not due to demand characteristics.

Keywords: Cognitive defusion; Deliteralization; Acceptance; Mindfulness; Self-relevant thoughts; Thought control; Believability of negative thoughts
\end{abstract}

\title{
1. Introduction
}

Negative thoughts have been a prominent focus of cognitive behavior therapy (CBT) since its inception. Because negative thoughts are related to negative emotions and actions, typically a wide variety of means are used in traditional CBT to reduce their frequency, intensity, or situational sensitivity, or to change them into more desirable forms. For example, negative thoughts may be logically disputed (Ellis, 1962), empirical tests may be arranged to assess their veracity (Beck, Rush, Shaw, \& Emery, 1979), or Socratic dialogues are used to learn to detect flaws in reasoning (Rutter \& Friedberg, 1999).

Recently, a new wave of cognitive behavior therapies have emerged that apply a more secondorder, contextual, or metacognitive approach to cognition (see Hayes, Follette, \& Linehan, in press and Hayes, Jacobson, Follette, \& Dougher, 1994, for book length reviews). In these methods there is little 
emphasis "on changing the content of thoughts; rather, the emphasis is on changing awareness of and relationship to thoughts" (Segal, Teasdale, \& Williams, in press: p. 13; emphasis in the original). Examples include Acceptance and Commitment Therapy (ACT; Hayes, Strosahl, \& Wilson, 1999), Dialectical Behavior Therapy (DBT; Linehan, 1993), and Mindfulness-Based Cognitive Therapy (MBCT; Segal, Williams, \& Teasdale, 2002), among many others (e.g. Borkovec \& Roemer, 1994; Jacobson \& Christensen, 1996; Marlatt, 2002).

All of these methods are complex packages, containing many components. Even relatively focused procedures are notsimple. Mindfulness, for example, includes acceptance, focusing on the present moment, taking a non-judgmental stance, attentional training, specific exercises, daily practice, and other elements. As the behavioral therapies explore these more contextual methods, it seems worthwhile to build a more elementary understanding of the possible processes they involve, but doing so will require research with much more focused components.

The elements of ACT lend themselves to such research, in part because they are linked to a theory of language and cognition: Relational Frame Theory (RFT; Hayes, Barnes-Holmes, \& Roche, 2001). RFT claims that language is based on learned bi-directional and combinatorial stimulus relations that alter the functions of events participating in relational networks. Both the relations among events, and the functions that are transformed by them are controlled by contextual features. For that reason it should be possible to change the impact of verbal/cognitive events simply by changing the literal and functional context in which they occur: what is termed "cognitive defusion".

There are dozens of cognitive defusion procedures used in ACT. There is support for the clinical effectiveness of ACT (see Hayes, Masuda, Bissett, Luoma, \& Guerrero, 2004), and some evidence that it works in part though cognitive defusion processes (e.g. Bach \& Hayes, 2002; Bond \& Bunce, 2000; Zettle $\&$ Hayes, 1986) butit is a large package and there is no research on the applied impact of any specific cognitive defusion component.

One component is particularly interesting for present purposes given its simplicity and long history. In one of the earliest textbooks on psychology, Titchener (1916: p. 425) argued that when a word is said aloud over and over again the context required for words to have literal meaning was removed. This technique is almost an archetype of procedures that attempt to change the function of a private event rather than its form or occurrence, since it involves an attempt to change function precisely by repeatedly producing the same form. In the middle part of the last century basic researchers examined this procedure and similar techniques (i.e. prolonged visual inspection and repeated writing of the stimulus word) under the label of "semantic satiation" (Amster, 1964; Esposito $\&$ Pelton, 1971). Several studies in that literature showed reductions in the literal meaning of repeated words (e.g. Lambert\& Jokobovits, 1960) particularly when a rationale was given (Esposito \& Pelton, 1971).

The present study sought preliminary evidence that this ACT defusion technique was psychologically active. If this technique results in the decreased believability and emotional impact of 
difficult thoughts, then more elaborate clinical comparisons using several such defusion techniques in a focused clinical package mightbe warranted.

2. Method

\subsection{Participants}

Eight female undergraduate students (18-19 years old) were recruited from an introductory psychology course subject pool. Participants fulfilled part of the course requirement and received $\$ 5$ for participation.

\subsection{Thought selection and assessment}

Participants were asked to generate two self-relevant negative thoughts that they found particularly disturbing (e.g. "I am too fat."). Participants were then asked to restate each thought in one word (e.g. "fat"). The degree of discomfort and the believability of each thought were then rated using a 100-mm Likert-style visual analog scale. Responses ranged from 0 (not at all uncomfortable) to 100 (very uncomfortable) for the discomfort scale, and from 0 (not at all believable) to 100 (very believable) for the believability scale. After the intervention procedures, these same rating were taken again.

\subsection{Procedure}

The first experiment compared the defusion technique and rationale with a simple distraction task presented without a rationale (reading about Japan). The second experiment provided a gross control for demand characteristics by comparing defusion to a "thought control" comparison condition and a rationale (later control studies tested for the adequacy of this control condition). Both studies use an alternating treatments design (Barlow \& Hayes, 1979) with four participants. One of the two restated thoughts (e.g. "fat") was randomly assigned to each condition being compared. Each intervention was given three times in random order but with no more than two consecutive trials of the same treatment condition.

Defusion rationale and training. At the beginning of the first cognitive defusion period, a 5minute rationale and training drawn from the ACT manual (Hayes etal., 1999) was provided. The rationale pointed out the benefits to civilization of literal language and thought (e.g. logical thinking and resulting control over the environment), but also emphasized the role of language and thought in human suffering. Negative thoughts may be relatively automatic, yet people often become "fused" with their literal content. To exemplify this, participants were asked to say the word "milk" once and to notice all of the functions that occur when it is heard (e.g. creamy, white, cold). The participant was then asked this time to repeat the word "milk" out loud as fast as possible for $30 \mathrm{~s}$ and to notice what happened. All participants described changes in which the meaning of the word began to disappear and its more direct functions emerged (e.g. "the word milk did not mean anything. It became just a sound."). The experimenter then asked the participant to apply this experience to his or her self-relevant negative thought, suggesting that negative thoughts are also in part simply words with conventional meanings, and thus can be experienced even when they are literally negative without being harmful. 
The procedure was then applied to the restated, self-relevant negative thought (e.g. "fat") that had been randomly assigned to this condition. The participant was asked to repeat the one-word thought out loud as fast as possible. The experimenter provided verbal prompts (e.g. "louder" and "faster") to the participant after 13 and $26 \mathrm{~s}$ and said "stop" after $30 \mathrm{~s}$.

Distraction task. The distraction condition did not include a rationale. Instead, the participant was simply asked to read an article on Japan for 5 min. During the "intervention" period, the participant was asked to continue to read the article for $30 \mathrm{~s}$.

Thought control rationale and exercise. At the beginning of the first thought control session, a 5minute rationale was provided. The rationale stressed that human cognition is the cause of human action and implicated negative thoughts as the core source of human suffering since they tend to lead to negative emotions and actions. To change this pattern we need to learn to remove negative thoughts by confronting them, changing them to more positive forms, distracting oneself from them, and suppressing them. Positive self-talk, positive imagery, and breathing training were explained and cast as examples of such control strategies. As an experiential exercise, the participant received a 30-second breathing training (i.e. abdominal breathing training). This was then applied to the restated, selfrelevant negative thought (e.g. "dumb") that had been randomly assigned to this condition. The participant was instructed that he or she could use any strategy including any of the methods mentioned so long as the purpose was not to think of the negative thought. The experimenter provided verbal prompts (e.g. "do not think of it") to the participant after 13 and 26 s and said "stop" after $30 \mathrm{~s}$.

\section{Results}

The initial amounts of discomfort and believability occasioned by each of the two thoughts for each participant are shown in Table 1. Because the precise initial values varied, all ratings after the initial assessment were converted into a standard ratio for the particular thought: obtained score/initial score. Thus, a score of 1 indicated no change, 0.5 indicated a $50 \%$ reduction, and so on.

Fig. 1 shows the standardized degree of discomfort and believability for the two targeted thoughts as function of the two conditions in Experiment 1. For all participants, the discomfort and believability of negative self-referential thoughts were lower following defusion than following distraction.

Fig. 2 shows discomfort and believability for the two targeted thoughts as function of the two conditions in Experiment 2. Results were very similar to those shown in Experiment 1. Discomfort and believability was lower following the defusion condition than for thought control condition for all participants.

\section{Control conditions}

The thought control condition was not meant to be an analog of actual clinical procedures (it does not precisely comport with any existing clinical packages), but it was meant to control for gross demand characteristics. This was examined in two ways. First, credibility ratings were gathered from 10 
additional participants who were recruited from the same subject pool (using the actual participants used in Experiment 2 seemed unwise since both procedures were used with each participant, and multiple treatment interference could occur). After thought selection and assessment half were randomly given the defusion rationale and half were given the thought control rationale, focused on one of the two thoughts. Participants then rated "how helpful they thought this procedure will be to cope with this particular thought" on a 7-point Likert scale, from 1 ("not at all helpful") to 7 ("extremely helpful"). The mean ratings for thought control and defusion were identical: 4.8 .

As a higher test of equivalence for the rationales, the impact of the rationale alone on the discomfort and believability of self-relevant negative thought was examined with 23 additional participants recruited from the same subject pool. After thought selection and assessment (with two thoughts), participants were randomly assigned to the defusion $(N=13)$ or thought control $(N=10)$ conditions. Exactly as in Experiment 2, participants were given the rationale and told to apply these methods to a target thought, but no practice with that thought then occurred before participants again rated the discomfort and believability of the thought. The mean rating of discomfort of the targeted thought at pre- and post-rationale were 68.4 and 65.5 for the defusion condition, $t(12)=0.50, p=0.63$, and 63.1 and 60.7 for the thought control condition, $t(9)=0.41, p=0.69$. The mean ratings of believability at pre- and post-rationale were 57.8 and 50.6 for the defusion condition, $t(12)=1: 31, p=$ 0.21 , and 54.7 and 41.4 for the thought control condition, $t(9)=3.00, p=0.02$. These results showed that the defusion rationale alone did not have a significant impact on the target thought, but that the thought control rationale did significantly reduce the believability of negative self-relevant thoughts. Given the superiority of the thought control rationale, these results suggest that the thought control condition provided a good control for general demand characteristics and credibility. The impact of the defusion condition seems to require more than the rationale, and the condition is psychologically active above and beyond gross demand characteristics.

\section{General discussion}

The present study suggests that repetition of negative self-referential words, at least when combined with a clinical rationale, can reduce their believability and their negative emotional impact. While single word mantras (e.g. "one") have long been known to reduce anxiety and stress (e.g. Benson, Alexander, \& Feldman, 1975) the present experiments are the first to show that the procedure alters the believability of negative self-referential thoughts and the discomfort they occasion, and does so in a fashion that fits with the hypothesized nature of defusion interventions more generally (see Hayes etal., 1999).

It seems possible that defusion underlies the impact of several of the new behavior therapies. The present data do not show, however, that Titchener's defusion procedure, or defusion procedures more generally, are actually clinically useful, and they provide no evidence that such procedures are better than any existing clinical intervention. That was not the purpose of the present study. Rather, the present study shows that defusion exercises and rationales are psychological active conditions that impact believability and discomfort in theoretically coherent ways. These data are subject to methodological limitations. Through accidents of random assignment, 13 out of 16 initial values of 
believability and discomfort of self-relevant thoughts were higher for cognitive defusion than comparison conditions among participants in the two experiments, for example. The results were similar for the other three values, however. The actual techniques used by each participant during the 30second thought suppression were also not clear, which limits what can be said about this condition and its comparison to the defusion technique. Control conditions that focus on more specific procedures might be helpful in analyzing defusion interventions in a theoretically interesting manner.

Titchener's insight from the early days of the last century seems correct. Additional work will be needed to see if this insight can help us understand the impact of the current set acceptance, defusion, and mindfulness focused procedures and to create more effective ones.

\section{References}

Amster, H. (1964). Semantic satiation and generation: Learning? Adaptation?. Psychological Bulletin, 62, 273-286.

Bach, P., \& Hayes, S. C. (2002). The use of Acceptance and Commitment Therapy to prevent the rehospitalization of psychotic patients: A randomized controlled trial. Journal of Consulting and Clinical Psychology, 70, 1129-1139.

Barlow, D. H., \& Hayes, S. C. (1979). Alternating treatments design: One strategy for comparing the effects of two treatments in a single subject. Journal of Applied Behavior Analysis, 12, 199-210.

Beck, A. T., Rush, A. J., Shaw, B. F., \& Emery, G. (1979). Cognitive therapy of depression. New York: Guilford Press.

Benson, H., Alexander, S., \& Feldman, C. L. (1975). Decreased premature ventricular contractions through use of the relaxation response in patients with stable ischemic heart disease. Lancet, 2 , 380-382.

Bond, F. W., \& Bunce, D. (2000). Mediators of change in emotion-focused and problem-focused worksite stress management interventions. Journal of Occupational Health Psychology, 5, 156-163.

Borkovec, T. D., \& Roemer, L. (1994). Generalized anxiety disorder. In R. T. Ammerman, \& M. Hersen (Eds.), Handbook of prescriptive treatments for adults (pp. 261-281). New York: Plenum.

Ellis, A. (1962). Reason and emotion in psychotherapy. New York: Lyle Stuart.

Esposito, N. J., \& Pelton, L. H. (1971). Review of the measurement of semantic satiation. Psychological Bulletin, 75, 330-346.

Hayes, S. C., Barnes-Holmes, D., \& Roche, B. (Eds.) (2001), Relational Frame Theory: A Post-Skinnerian account of human language and cognition. New York: Plenum Press.

Hayes, S. C., Follette, V. M., \& Linehan, M. (Eds.) (in press). Mindfulness, acceptance, and relationship. New York: Guilford Press.

Hayes, S. C., Jacobson, N. S., Follette, V. M., \& Dougher, M. J. (Eds.) (1994), Acceptance and change: Content and context in psychotherapy. Reno, NV: Context Press.

Hayes, S. C., Masuda, A., Bissett, R., Luoma, J., \& Guerrero, L. F. (2004). DBT, FAP, and ACT: How empirically oriented are the new behavior therapy technologies?. Behavior Therapy, 35, 35-54.

Hayes, S. C., Strosahl, K. D., \& Wilson, K. G. (1999). Acceptance and Commitment Therapy: An experiential approach to behavior change. New York: Guilford Press. 
Jacobson, N. S., \& Christensen, A. (1996). Integrative couple therapy: Promoting acceptance and change. New York, NY: Norton.

Lambert, W. E., \& Jokobovits, L. A. (1960). Verbal satiation and changes in the intensity of meaning. Journal of Experimental Psychology, 60, 376-383.

Linehan, M. M. (1993). Cognitive-behavioral treatment of borderline personality disorder. New York: Guilford.

Marlatt, G. A. (2002). Buddhist philosophy and the treatment of addictive behavior. Cognitive \& Behavioral Practice, 9, 44-49.

Rutter, J. G., \& Friedberg, R. D. (1999). Guidelines for the effective use of Socratic dialogue in cognitive therapy. In VandeCreek, \& T. L. Jackson (Eds.), Innovations in clinical practice: A source book, Vol. 17. (pp. 481-490). Sarasota, FL: Professional Resource Press/Professional Resource Exchange, Inc.

Segal, Z. V., Teasdale, J. D., \& Williams, J. M. G. (in press). Mindfulness-based cognitive therapy: Theoretical rationale and empirical status. In S. C. Hayes, V. M. Follette, \& M. Linehan (Eds.), Mindfulness, acceptance, and relationship. New York: Guilford Press.

Segal, Z. V., Williams, J. M. G., \& Teasdale, J. D. (2002). Mindfulness-based cognitive therapy for depression: A new approach to preventing relapse. New York: Guilford Press.

Titchener, E. B. (1916). A text-book of psychology. New York: MacMillan.

Zettle, R. D., \& Hayes, S. C. (1986). Dysfunctional control by client verbal behavior: The context of reason-giving. Analysis of Verbal Behavior, 4, 30-38 
Table 1

Initial discomfort and believability for the two thoughts used by each participant in Experiments 1 and 2

\begin{tabular}{|c|c|c|c|c|}
\hline & \multicolumn{2}{|c|}{ Defusion } & \multicolumn{2}{|c|}{ Distraction } \\
\hline & Discomfort & Believability & Discomfort & Believability \\
\hline \multicolumn{5}{|l|}{ Experiment 1} \\
\hline Participant 1 & 75 & 95 & 54 & 81 \\
\hline Participant 2 & 76 & 43 & 44 & 18 \\
\hline Participant 3 & 65 & 71 & 47 & 75 \\
\hline \multirow[t]{3}{*}{ Participant 4} & 84 & 84 & 67 & 75 \\
\hline & \multicolumn{2}{|c|}{ Defusion } & \multicolumn{2}{|c|}{ Thought Control } \\
\hline & Discomfort & Believability & Discomfort & Believability \\
\hline \multicolumn{5}{|l|}{ Experiment 2} \\
\hline Participant 5 & 76 & 19 & 30 & 5 \\
\hline Participant 6 & 63 & 51 & 61 & 27 \\
\hline Participant 7 & 80 & 95 & 71 & 85 \\
\hline Participant 8 & 25 & 6 & 29 & 15 \\
\hline
\end{tabular}




\section{Figure 1}

The impact of defusion and a simple distraction condition across four participants on the discomfort and believability associated with two negative thoughts.

Discomfort
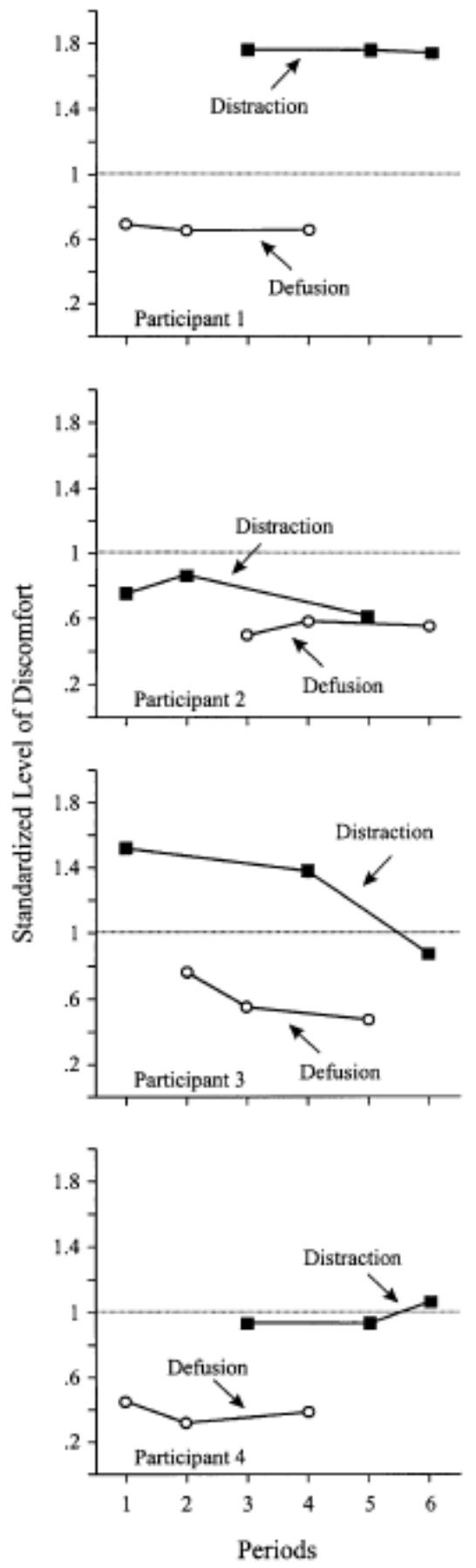

Believability
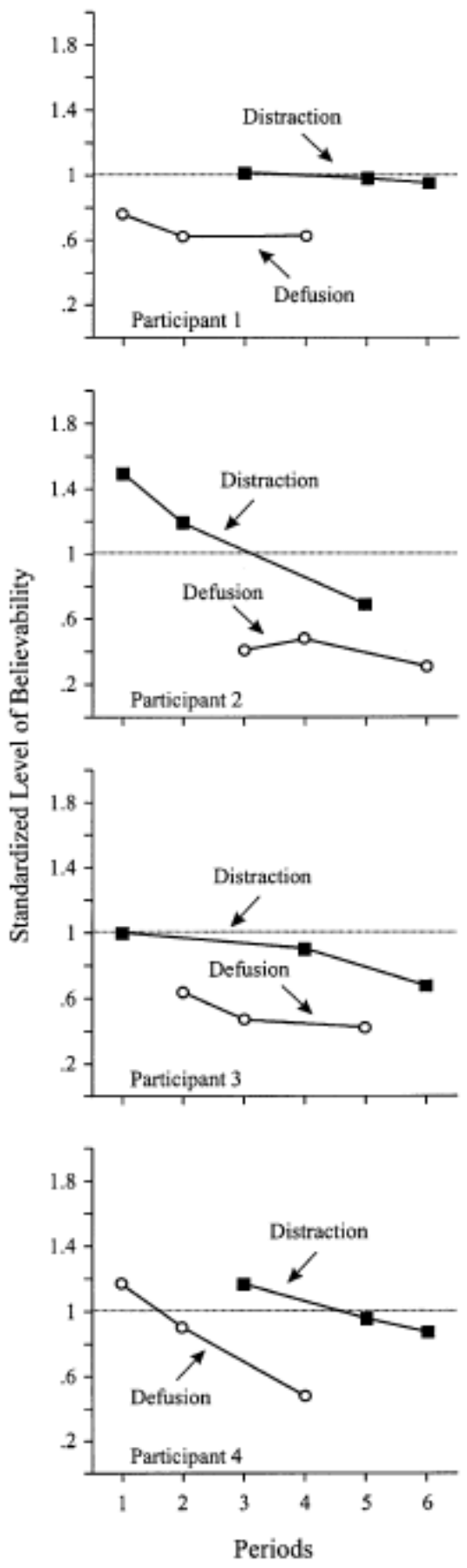


\section{Figure 2}

The impact of defusion and a thought control condition across four participants on the discomfort and believability associated with two negative thoughts.

\section{Discomfort}
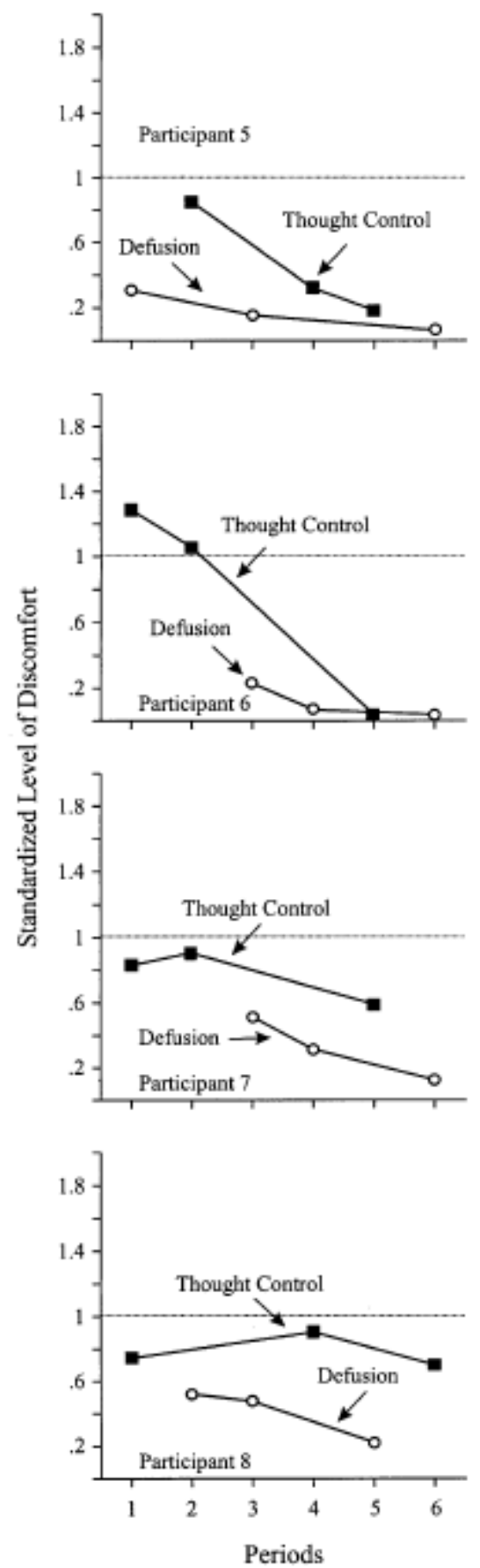

Believability
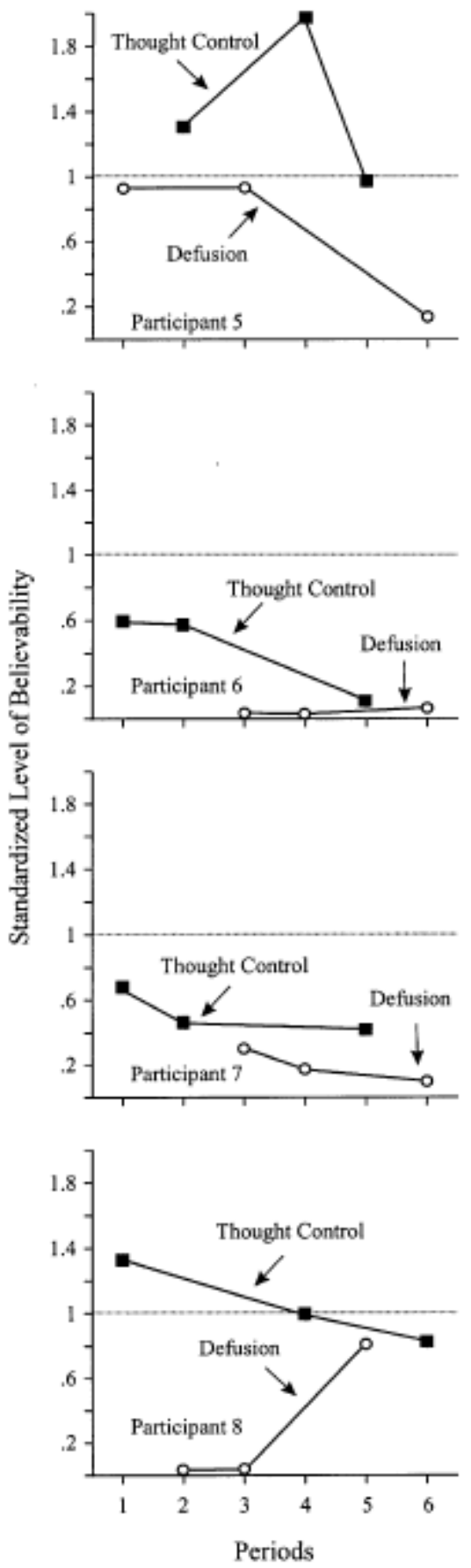